\title{
Mean platelet volume/platelet count ratio in colorectal cancer: a retrospective clinical study
}

\author{
Yang-Yang $W^{\dagger}{ }^{\dagger}$ Xuan Zhang ${ }^{\dagger}$, Yuan-Yuan Qin, Jin-Qiu Qin and Fa-Quan Lin ${ }^{*}$
}

\begin{abstract}
Background: Mean platelet volume (MPV) is a marker of platelet activation. MPV and platelet count (PC) are negatively correlated, and their ratio (MPV/PC) is informative for the diagnosis of malignant tumors. However, the relationship between MPV/PC and colorectal cancer is unclear. This retrospective clinical study aimed to evaluate the diagnostic value of MPV/PC in colorectal cancer.
\end{abstract}

Methods: Hematological examinations were performed at initial diagnosis in patients with colorectal cancer $(n=186)$ or adenomatous polyp $(n=132)$ and healthy controls $(n=108)$. Hematological parameters evaluated included white blood cells, red blood cells, hemoglobin, neutrophils, lymphocytes, monocytes, PC, and MPV. Statistical analyses included Student's t-test, one-way ANOVA or Kruskal-Wallis H test, chi-square tests, Spearman's correlation test and receiver operating characteristic (ROC). ROC curve was used to evaluate the diagnostic values of MPV and MPV/PC in colorectal cancer.

Results: Among these groups, MPV was significantly lower in colorectal cancer than in adenomatous polyp ( $p=0.002)$ and healthy controls $(p<0.001)$ but did not significantly differ between adenomatous polyp and healthy controls $(p=0$. 210). MPV/PC was lower in colorectal cancer compared with adenomatous polyp and healthy controls $(p<0.001)$ and in adenomatous polyp compared with healthy controls $(p=0.010)$. MPV did not significantly differ among colorectal cancer subgroups, while MPV/PC significantly differed between TNM stages and the presence/absence of lymph node metastasis. MPV/PC was negatively correlated with the neutrophil to lymphocyte ratio(NLR) $(p=0.002)$ and platelet to lymphocyte ratio(PLR) concentration ( $p<0.001)$. In the differential diagnosis between colorectal cancer and adenomatous polyp, MPV/ PC produced a larger ROC curve than MPV, NLR or PLR alone. Using MPV/PC to distinguish between colorectal cancer and controls produced a larger AUC than using MPV or NLR alone.

Conclusions: MPV/PC may be useful for the diagnosis of colorectal cancer. However, further studies are warranted to include additional regions and more data, to assess the utility of MPV/PC as a novel diagnostic screening tool for colorectal cancer.

Keywords: Mean platelet volume/platelet count ratio, Colorectal cancer, Adenomatous polyp

\footnotetext{
* Correspondence: fqlin1998@163.com

${ }^{\dagger}$ Yang-Yang Wu and Xuan Zhang contributed equally to this work.

Department of Clinical Laboratory, the First Affiliated Hospital of Guangxi

Medical University, Nanning 530021, Guangxi Zhuang Autonomous Region,

China
}

(c) The Author(s). 2019 Open Access This article is distributed under the terms of the Creative Commons Attribution 4.0 International License (http://creativecommons.org/licenses/by/4.0/), which permits unrestricted use, distribution, and reproduction in any medium, provided you give appropriate credit to the original author(s) and the source, provide a link to the Creative Commons license, and indicate if changes were made. The Creative Commons Public Domain Dedication waiver (http://creativecommons.org/publicdomain/zero/1.0/) applies to the data made available in this article, unless otherwise stated. 


\section{Background}

Colorectal cancer is the third most common malignant tumor and the fourth leading cause of cancer-related deaths worldwide [1]. In China, there were 376,300 new cases of colorectal cancer, and 191,000 cases died of colorectal cancer in 2015 [2]. It is estimated that there will be more than 1.8 million new colorectal cancer cases and 881,000 deaths worldwide in 2018 [3]. Colorectal cancer takes years or even decades to develop, and many people do not develop clinical manifestations such as abdominal pain or intestinal bleeding until cancer metastasizes [4, 5]. Although patients with colorectal cancer can be treated with a combination of surgery, chemotherapy, and radiotherapy, a high recurrence rate, and distant metastases still threaten a large proportion of patients [6]. At present, colonoscopy dramatically improves the diagnostic rate of colorectal cancer, but its application is limited by its invasiveness, high cost, and inconvenience of operation [4]. Therefore, it is necessary to find a sensitive and straightforward index for the diagnosis of colorectal cancer.

The mean platelet volume (MPV) reflects the size of platelets, which is related to platelet production and activation [7, 8]. Studies have found that MPV is closely related to many kinds of tumors, such as colon cancer, thyroid cancer, and renal cell carcinoma [7, 9, 10]. Additionally, it has been shown that there is an inverse relationship between MPV and platelet count (PC), suggesting that these two variables should be interpreted as a ratio rather than being used alone [11-13]. Both MPV and PC are commonly available because they are inexpensive and simple parameters of whole blood counts, which are used as routine examination items in outpatients and inpatients.

Recently, much attention has been directed to the clinical value of the $\mathrm{MPV} / \mathrm{PC}$ ratio in malignant tumors including hepatocellular carcinoma, pancreatic cancer, lung cancer, and other diseases [14-16]. However, as far as we know, the relationship between MPV/PC and colorectal cancer has not been reported. The purpose of this study was to investigate the relationship between $\mathrm{MPV} / \mathrm{PC}$ and the clinicopathological features of colorectal cancer and to evaluate its value for the diagnosis of colorectal cancer.

\section{Methods}

\section{Study population}

This study retrospectively analyzed the patients with colorectal cancer who were first diagnosed in the First Affiliated Hospital of Guangxi Medical University between June 2012 and May 2018. Patients who had undergone surgical resection after being diagnosed with colorectal cancer but did not receive pharmacological treatment were included in the study. The exclusion criteria were as follows: pregnancy or lactation, other malignancies, thyroid disease, diabetes, cardiovascular disease, autoimmune diseases (such as idiopathic thrombocytopenic purpura), kidney disease, hematological disease, or blood transfusion within 3 months before admission. One hundred and eighty-six patients with colorectal cancer were included in the study and all patients were staged according to the 7th edition of the United States Joint Cancer Committee (UICC/AJCC) TNM staging criteria. One hundred and thirty-two patients diagnosed with colorectal adenomatous polyp were assigned to the adenomatous polyp group. Simultaneously, one hundred and eight healthy subjects were selected as the control group. There was no significant difference in gender or age between the three groups. The study was approved by the Ethics Committee of the First Affiliated Hospital of Guangxi Medical University. All the participants gave written informed consent.

\section{Clinical measurements and calculation}

Fasting venous blood was taken into an ethylenediaminetetraacetic acid- $\mathrm{K}_{2}$ anticoagulant tube and a dry tube early during the early morning. A Beckman 780 blood cell analyzer (Beckman Coulter, Brea, CA) was used for the routine examination of blood samples. The laboratory data included white blood cells, red blood cells, hemoglobin, platelets, neutrophils, lymphocytes, monocytes, and mean platelet volumes. MPV/PC values were calculated from the mean platelet volume and the platelet count.NLR values were calculated from the neutrophil and the lymphocyte. PLR values were calculated from the platelet count and the lymphocyte.

\section{Statistical analyses}

The continuous variable data are expressed as mean \pm standard deviation or median (interquartile range), and the categorical variable data are expressed in terms of frequency or rate. All data were statistically analyzed using the software programs SPSS 20.0 (IBM, Armonk, NY, USA), MedCalc 15.0 (MedCalc Software, Mariakerke, Belgium), and Prism 5 (GraphPad Software, San Diego, CA, USA). Data were compared between two groups by Student's $t$-test. Data were compared between three groups by one-way ANOVA or Kruskal-Wallis $\mathrm{H}$ test. The Chi-square test was used for the comparison of rates. Correlations were analyzed by Spearman's correlation test. The receiver operating characteristic (ROC) curve was used to calculate the sensitivity, specificity, positive predictive value, negative predictive value, and area under the curve (AUC), and to evaluate the diagnostic values of MPV and MPV/PC in colorectal cancer. Statistical significance was defined as $p<0.05$. 


\section{Results}

\section{Clinical characteristics of the subjects}

The clinical characteristics of colorectal cancer, adenomatous polyp, and control groups are shown in Table 1. There was no significant difference in sex or age among the three groups. The values of MPV and MPV/PC in colorectal cancer, adenomatous polyp, and control groups are shown in Fig. 1. MPV was significantly lower in the colorectal cancer group than in the adenomatous polyp and control groups (cancer vs. adenomatous polyp, $p=0.002$; cancer vs. control, $p<0.001)$. However, MPV did not significantly differ between the adenomatous polyp and control groups $(p=0.210)$. The MPV/PC was lower in the colorectal cancer group compared with the adenomatous polyp and control groups (both $p<$ 0.001 ) and in the adenomatous polyp group compared with the control group $(p=0.010)$.

\section{Differences in MPV and MPV/PC among subgroups of colorectal cancer}

The clinicopathological features of colorectal cancer subgroups and their preoperative values of MPV and MPV/ $\mathrm{PC}$ are shown in Table 2. The MPV showed no significant differences among the subgroups regarding TNM stage, serosal invasion, lymph node metastasis, or distant metastasis. However, MPV/PC significantly differed between patients with stage I/II and stage III/IV cancer. Moreover, there was a significant difference in MPV/PC between patients with and without lymph node metastasis. The $\mathrm{MPV} / \mathrm{PC}$ showed no significant differences among serosal invasion stages or between patients with and without distant metastasis.

\section{Correlations between MPV, MPV/PC and other hematological measures of inflammation}

Correlation analysis demonstrated that the MPV negatively correlated with PLR $(r=-0.207, p<0.001)$. However, the MPV did not correlate with NLR $(p>0.05)$.

Correlation analysis demonstrated that the MPV/PC was negatively correlated with the NLR $(r=-0.148, p=0.002)$ and PLR concentration $(r=-0.575, p<0.001)$.

\section{Diagnostic values of MPV, MPV/PC, NLR and PLR for differentiating between colorectal cancer and adenomatous polyp or controls}

As shown in Table 3, with the adenomatous polyp as the reference, the specificity of MPV/PC was highest at 52.15 in colorectal cancer as compared with the adenomatous polyp. As shown in Table 4, with the controls as references, the specificity of $\mathrm{MPV} / \mathrm{PC}$ was highest at 68.82 in colorectal cancer as compared with controls. Using MPV/PC to distinguish between colorectal cancer and adenomatous polyp produced a larger AUC than using MPV, NLR or PLR alone (all $p<0.05$ ) (Fig. 2a). Using $\mathrm{MPV} / \mathrm{PC}$ to distinguish between colorectal cancer and controls produced a larger AUC than using MPV or NLR alone (both $p<0.001$ ) (Fig. 2b).

\section{Discussion}

At present, the mechanistic relationship between MPV/ $\mathrm{PC}$ and the occurrence or progression of malignant

Table 1 Clinical characteristics of colorectal cancer, adenomatous polyp, and control groups

\begin{tabular}{|c|c|c|c|c|}
\hline Parameters & $\begin{array}{l}\text { Colorectal cancer group } \\
(n=186)\end{array}$ & $\begin{array}{l}\text { Adenomatous polyp group } \\
(n=132)\end{array}$ & $\begin{array}{l}\text { Control group } \\
(n=108)\end{array}$ & $p$-value \\
\hline Age (years) & $54.56 \pm 12.18$ & $52.55 \pm 12.16$ & $53.34 \pm 14.18$ & 0.369 \\
\hline Male (\%) & $111(59.7 \%)$ & 79 (59.8\%) & $65(60.2 \%)$ & 0.996 \\
\hline WBC $\left(10^{9} / \mathrm{L}\right)$ & $6.77 \pm 1.64^{a}$ & $6.32 \pm 1.61$ & $6.23 \pm 1.02^{c}$ & 0.003 \\
\hline $\operatorname{RBC}\left(10^{12} / \mathrm{L}\right)$ & $4.42 \pm 0.63^{a}$ & $4.78 \pm 0.72$ & $4.73 \pm 0.42^{c}$ & $<0.001$ \\
\hline $\mathrm{Hb}(\mathrm{g} / \mathrm{L})$ & $121.27 \pm 23.07^{a}$ & $132.12 \pm 20.03^{b}$ & $142.47 \pm 11.80^{c}$ & $<0.001$ \\
\hline Neutrophil $\left(10^{9} / \mathrm{L}\right)$ & $3.92 \pm 1.26^{a}$ & $3.57 \pm 1.26$ & $3.40 \pm 0.79^{c}$ & $<0.001$ \\
\hline Lymphocyte $\left(10^{9} / \mathrm{L}\right)$ & $1.99 \pm 0.58$ & $1.99 \pm 0.60^{b}$ & $2.18 \pm 0.51^{c}$ & 0.010 \\
\hline Monocyte $\left(10^{9} / \mathrm{L}\right)$ & $0.53 \pm 0.19$ & $0.50 \pm 0.17^{b}$ & $0.45 \pm 0.15^{c}$ & 0.001 \\
\hline Platelet count $\left(10^{9} / \mathrm{L}\right)$ & $279.80 \pm 80.56^{a}$ & $223.89 \pm 42.59^{b}$ & $207.83 \pm 37.40^{c}$ & $<0.001$ \\
\hline MPV (fl) & $8.48 \pm 1.10^{a}$ & $8.83 \pm 0.90$ & $8.98 \pm 0.77^{c}$ & $<0.001$ \\
\hline MPV/PC & $0.0330 \pm 0.0112^{a}$ & $0.0411 \pm 0.0112^{b}$ & $0.0447 \pm 0.0096^{c}$ & $<0.001$ \\
\hline NLR & $1.98(1.50-2.51)^{a}$ & $1.67(1.37-2.27)^{\mathrm{b}}$ & $1.51(1.24-1.92)^{\mathrm{C}}$ & $<0.001$ \\
\hline PLR & $140.26(107.11-182.96)^{a}$ & $113.03(90.98-143.81)^{b}$ & $94.55(76.62-116.42)^{c}$ & $<0.001$ \\
\hline
\end{tabular}

WBC white blood cells, $H b$ hemoglobin, MPV mean platelet volume, MPV/PC the ratio between MPV and platelet count, NLR neutrophil to lymphocyte ratio, PLR platelet to lymphocyte ratio

${ }^{a}$ Colorectal cancer group vs. adenomatous polyp group $(p<0.05)$

${ }^{\mathrm{b}}$ Adenomatous polyp group vs. control group $(p<0.05)$

${ }^{\mathrm{c} C o l o r e c t a l}$ cancer group vs. control group $(p<0.05)$ 


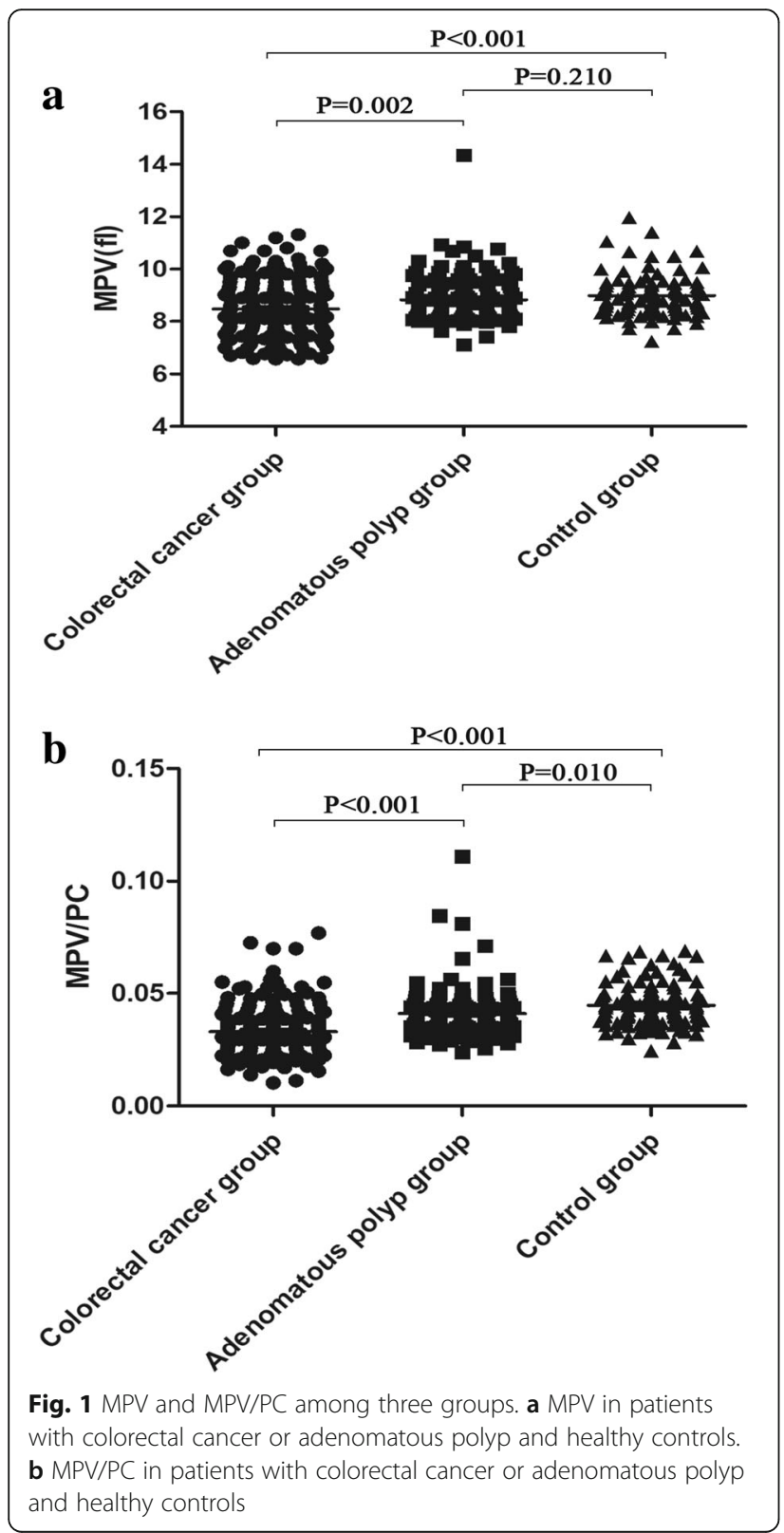

tumors remains unclear, but there are relatively more studies on MPV and PC separately than on MPV/PC. MPV represents the volume of platelets in the blood circulation and reflects their functional state [7, 13]. MPV is also an indicator of inflammatory diseases and is related to disease activity/severity $[17,18]$.

Studies have shown that inflammation is associated with the occurrence, development, and metastasis of multiple types of tumors [19-21]. The mechanisms may be related to the following reasons. First, inflammatory cells induce reactive oxygen species (ROS) production in cells, causing DNA damage and inhibiting DNA repair after injury, leading to tumorigenesis. Second, in the tumor microenvironment, inflammatory cells can secrete
Table 2 MPV and MPV/PC among subgroups of colorectal cancer patients

\begin{tabular}{cccccc}
\hline Parameters & $n$ & MPV & $p$-value & MPV/PC & $p$-value \\
\hline TNM stage & & & & & \\
I/I & 92 & $8.37 \pm 1.11$ & 0.165 & $0.0311 \pm 0.0089$ & 0.021 \\
III/IV & 94 & $8.59 \pm 1.08$ & & $0.0349 \pm 0.0129$ &
\end{tabular}

Serosal invasion stage

$\begin{array}{llllll}\mathrm{T} 1 / \mathrm{T} 2 & 39 & 8.22 \pm 0.99 & 0.092 & 0.0316 \pm 0.0100 & 0.404 \\ \mathrm{~T} 3 / \mathrm{T} 4 & 147 & 8.55 \pm 1.11 & & 0.0333 \pm 0.0115 & \end{array}$

Lymph node metastasis

$\begin{array}{llllll}\text { Absence } & 93 & 8.37 \pm 1.10 & 0.164 & 0.0308 \pm 0.0088 & 0.009 \\ \text { Presence } & 93 & 8.59 \pm 1.08 & & 0.0351 \pm 0.0129 & \end{array}$

Distant metastasis

$\begin{array}{llllll}\text { Absence } & 173 & 8.46 \pm 1.08 & 0.306 & 0.0329 \pm 0.0113 & 0.697\end{array}$

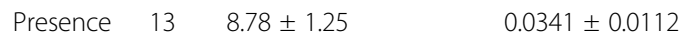

MPV mean platelet volume, MPV/PC ratio between MPV and platelet count

many cytokines, chemokines, and adhesion molecules in addition to promoting cell proliferation and angiogenesis, and these events promote tumor development and metastasis [22-24]. A decrease in MPV has also been implicated in locally advanced esophageal squamous cell carcinoma, gastric cancer, and bone marrow metastasis with solid tumors [25-27]. Platelets are non-nucleated cells that are produced by bone marrow megakaryocytes and are related to inflammation and thrombosis [28, 29]. Tumor cells associate with various cytokines such as platelet-derived growth factor, vascular endothelial growth factor, and other growth factors that stimulate platelet production [30]. Elevated platelet counts can produce more $\mathrm{CD} 40 \mathrm{~L}$ and promote an inflammatory response [29, 31, 32].Increased degradation of large platelets under inflammation may lead to a decrease in MPV, possibly because larger platelets are more responsive to stimulation, and a significant number of larger platelets are more likely to be selectively degraded [25].

In our study, the MPV values in the colorectal cancer group were significantly lower than those in the adenomatous polyp and control groups, which is in

Table 3 Diagnostic performances of MPV, MPV/PC, NLR and PLR for distinguishing colorectal cancer from an adenomatous polyp

\begin{tabular}{llllll}
\hline Marker & sensitivity & specificity & PPV & NPV & AUC $(95 \% \mathrm{Cl})$ \\
\hline MPV & 96.97 & 33.33 & 50.8 & 93.9 & $0.607(0.551-0.661)$ \\
MPV/PC & 89.39 & 52.15 & 57.0 & 87.4 & $0.739(0.687-0.787)$ \\
NLR & 72.73 & 44.62 & 48.2 & 69.7 & $0.579(0.523-0.634)$ \\
PLR & 89.39 & 37.63 & 50.4 & 83.3 & $0.654(0.599-0.706)$
\end{tabular}

MPV mean platelet volume, MPV/PC ratio between MPV and platelet count, NLR neutrophil to lymphocyte ratio, PLR platelet to lymphocyte ratio, $P P V$ positive predictive value, NPV negative predictive value, AUC $(95 \% \mathrm{Cl})$ area under the receiver operating characteristic curve ( $95 \%$ confidence interval) 
Table 4 Diagnostic performances of MPV, MPV/PC, NLR and PLR for distinguishing colorectal cancer from healthy controls

\begin{tabular}{llllll}
\hline Marker & sensitivity & specificity & PPV & NPV & AUC $(95 \% \mathrm{Cl})$ \\
\hline MPV & 92.59 & 44.62 & 49.3 & 91.2 & $0.659(0.602-0.713)$ \\
MPV/PC & 87.04 & 68.82 & 61.8 & 90.1 & $0.813(0.764-0.856)$ \\
NLR & 77.78 & 52.15 & 48.6 & 80.2 & $0.673(0.616-0.726)$ \\
PLR & 80.56 & 65.05 & 57.2 & 85.2 & $0.777(0.725-0.824)$ \\
\hline
\end{tabular}

MPV mean platelet volume, MPV/PC ratio between MPV and platelet count, $N L R$ neutrophil to lymphocyte ratio, $P L R$ platelet to lymphocyte ratio, $P P V$ positive predictive value, NPV negative predictive value, AUC $(95 \% \mathrm{Cl})$ area under the receiver operating characteristic curve ( $95 \%$ confidence interval)

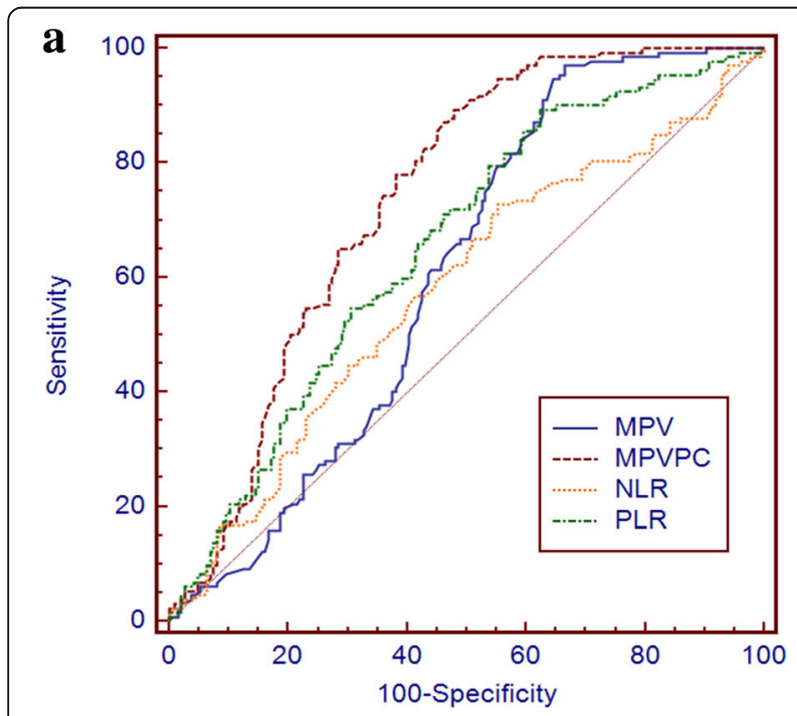

b

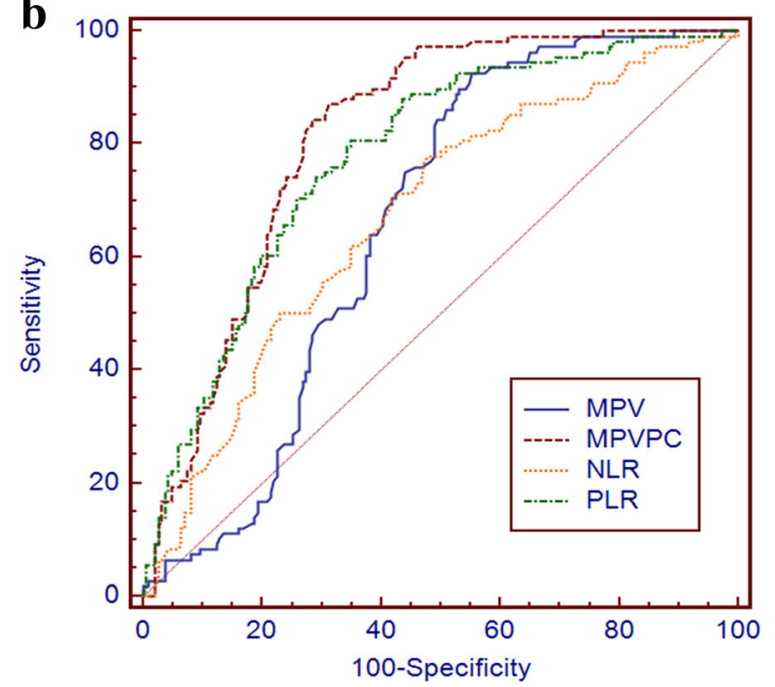

Fig. 2 Diagnostic performances. a Diagnostic performances of MPV, MPV/PC, NLR, and PLR for distinguishing colorectal cancer from an adenomatous polyp. $\mathbf{b}$ Diagnostic performances of MPV, MPV/PC, NLR, and PLR for distinguishing colorectal cancer from healthy control agreement with the findings reported by Cengiz et al. [33]. Sun et al. [25] found that MPV and MPV/PC were significantly decreased in patients with newly diagnosed locally advanced esophageal squamous cell carcinoma as compared to healthy controls. Inagaki et al. [34] found that the MPV and MPV/PC were significantly decreased in patients with non-small cell lung cancer as compared with controls. In our study, MPV/PC was significantly lower in the colorectal cancer group than in both the adenomatous polyp and control groups. Furthermore, MPV/PC negatively correlated with the NLR and PLR concentration. NLR and PLR are hematological measures of inflammation, which are related to several cancer types, including colorectal cancer, and renal cell carcinoma [35, 36]. Therefore, we speculate that the decrease of MPV/PC in colorectal cancer patients may be associated with an inflammatory reaction and suggest that it may be used as a marker to distinguish between benign and malignant colorectal tumors. MPV/PC is obtained by calculating the ratio of MPV to PC, which integrates the morphology and quantity of platelets and has a better diagnostic and predictive value than either parameter alone. The inverse relationship between MPV and PC may reflect the physiological tendency to maintain hemostasis $[14,37]$. We also found that MPV showed no significant differences among subgroups regarding TNM stage, serosal invasion, lymph node metastasis or distant metastasis. The MPV/PC was significantly different in subgroups between patients with stage I/II and stage III/IV cancer. Moreover, there was a significant difference in MPV/PC between patients with and without lymph node metastasis. Therefore, we believe that MPV/PC may be useful for the differential diagnosis of early and advanced colorectal cancer.

In ROC curve analysis, a larger AUC indicates a better diagnostic efficiency. Cho et al. [14] found that the MPV/PC ratio showed a better result than MPV alone when using the AUC to evaluate the efficacy of MPV/PC for distinguishing between patients with hepatocellular carcinoma and healthy controls. Concordantly, when we used ROC curves to analyze the performance of MPV/ PC for distinguishing colorectal cancer from benign colorectal polyps, MPV/PC showed superior diagnostic performance than using MPV, NLR or PLR alone. Using $\mathrm{MPV} / \mathrm{PC}$ to distinguish between colorectal cancer and controls produced a larger AUC than using MPV or NLR alone.

Accordingly, we believe that MPV/PC may be a promising diagnostic biomarker for colorectal cancer.

This study had some limitations, as follows. First, relatively few cases were enrolled, and the conclusions need to be confirmed by large-scale multicenter clinical studies. Second, this study had a retrospective design, which cannot completely resolve some confounding factors 
and may produce a certain degree of deviation. Finally, we were not able to follow up patients with colorectal cancer and analyze the disease recurrence or the post-surgery status. Nevertheless, this study is the first to explore the relationship between MPV/PC and the clinicopathological features of colorectal cancer and assess its diagnostic value for colorectal cancer. The results highlight the possibility that MPV/PC could be used for the early detection and diagnosis of colorectal cancer.

\section{Conclusions}

MPV/PC may be a useful diagnostic marker for distinguishing between benign and malignant colorectal tumors and between early and advanced colorectal cancer.

\section{Abbreviations \\ AUC (95\% Cl): Area under the receiver operating characteristic curve (95\% confidence interval); Hb: Hemoglobin; MPV: Mean platelet volume; MPV/ PC: Ratio between MPV and platelet count; NLR: Neutrophil to lymphocyte ratio; NPV: Negative predictive value; PC: Platelet count; PLR: Platelet to lymphocyte ratio; PPV: Positive predictive value; ROC: Receiver operating characteristic; WBC: White blood cells}

\section{Acknowledgments}

We thank the Department of Clinical Laboratory, the First Affiliated Hospital of Guangxi Medical University, China.

\section{Funding}

This research received no external funding.

\section{Availability of data and materials}

The datasets used and/or analysed during the current study are available from the corresponding author on reasonable request.

\section{Authors' contributions}

YYW and XZ collated study data, assisted with the study data analysis, and wrote the manuscript. YYQ conceived the idea and designed the study. JQQ collected data, carried out the statistical analysis and interpreted the results. FQL revised the manuscript. All authors reviewed the manuscript and agreed to this information before submission.

\section{Ethics approval and consent to participate}

The study was approved by the Ethics Committee of the First Affiliated Hospital of Guangxi Medical University. All the participants gave written informed consent.

\section{Consent for publication}

Not applicable.

\section{Competing interests}

The authors declare that they have no competing interests.

\section{Publisher's Note}

Springer Nature remains neutral with regard to jurisdictional claims in published maps and institutional affiliations.

\section{Received: 18 November 2018 Accepted: 21 March 2019} Published online: 04 April 2019

\section{References}

1. Ahmed S, Johnson K, Ahmed O, Iqbal N. Advances in the management of colorectal cancer: from biology to treatment. Int J Color Dis. 2014;29:103142.

2. Chen W, Zheng R, Baade PD, Zhang S, Zeng H, Bray F, et al. Cancer statistics in China, 2015. CA Cancer J Clin. 2016;66:115-32.
3. Bray F, Ferlay J, Soerjomataram I, Siegel RL, Torre LA, Jemal A. Global cancer statistics 2018: GLOBOCAN estimates of incidence and mortality worldwide for 36 cancers in 185 countries. CA Cancer J Clin. 2018;68:394-424.

4. Mahasneh A, Al-Shaheri F, Jamal E. Molecular biomarkers for an early diagnosis, effective treatment and prognosis of colorectal cancer: current updates. Exp Mol Pathol. 2017;102:475-83.

5. Bardhan K, Liu K. Epigenetics and colorectal cancer pathogenesis. Cancers (Basel). 2013;5:676-713.

6. Li N, Yu Z, Zhang X, Liu T, Sun YX, Wang RT, et al. Elevated mean platelet volume predicts poor prognosis in colorectal cancer. Sci Rep. 2017;7:10261.

7. Li JY, Li Y, Jiang Z, Wang RT, Wang XS. Elevated mean platelet volume is associated with presence of colon cancer. Asian Pac J Cancer Prev. 2014;15: 10501-4.

8. Elsayed AM, Mohamed GA. Mean platelet volume and mean platelet volume/platelet count ratio as a risk stratification tool in the assessment of severity of acute ischemic stroke. Alexandria J Med. 2017;53:67-70.

9. Yu YJ, Li N, Yun ZY, Niu Y, Xu JJ, Liu ZP, et al. Preoperative mean platelet volume and platelet distribution associated with thyroid cancer. Neoplasma. 2017;64:594-8.

10. Yun ZY, Zhang X, Liu ZP, Liu T, Wang RT, Chen H. Association of decreased mean platelet volume with renal cell carcinoma. Int J Clin Oncol. 2017;22: $1076-80$.

11. Lozano M, Narváez J, Faúndez A, Mazzara R, Cid J, Jou JM, et al. Platelet count and mean platelet volume in the Spanish population. Med Clin (Barc). 1998;110:774-7.

12. Bessman JD, Williams LJ, Gilmer PR Jr. Mean platelet volume. The inverse relation of platelet size and count in normal subjects, and an artifact of other particles. Am J Clin Pathol. 1981;76:289-93.

13. Biricik S, Narcı H, Dündar GA, Ayrik C, Türkmenoğlu MÖ. Mean platelet volume and the ratio of mean platelet volume to platelet count in the diagnosis of acute appendicitis. Am J Emerg Med. 2019;37:411-4.

14. Cho SY, Yang JJ, You E, Kim BH, Shim J, Lee HJ, et al. Mean platelet volume/ platelet count ratio in hepatocellular carcinoma. Platelets. 2013;24:375-7.

15. Gong X, Zhang L, Yang D, Xiao X, Wei L, Wu L, et al. Mean platelet volume/ platelet count ratio is associated with prognosis in patients with pancreatic cancer. Int J Clin Exp Med. 2016;9:16379-86.

16. Omar M, Tanriverdi O, Cokmert S, Oktay E, Yersal O, Pilancı KN, et al. Role of increased mean platelet volume (MPV) and decreased MPV/platelet count ratio as poor prognostic factors in lung cancer. Clin Respir J. 2018;12:922-9.

17. Ozdemir R, Karadeniz C, Doksoz O, Celegen M, Yozgat Y, Guven B, et al. Are mean platelet volume and platelet distribution width useful parameters in children with acute rheumatic carditis? Pediatr Cardiol. 2014;35:53-6.

18. Beyazit Y, Sayilir A, Torun S, Suvak B, Yesil Y, Purnak T, et al. Mean platelet volume as an indicator of disease severity in patients with acute pancreatitis. Clin Res Hepatol Gastroenterol. 2012;36:162-8.

19. Rasic I, Radovic S, Aksamija G. Relationship between chronic inflammation and the stage and histopathological size of colorectal carcinoma. Med Arch. 2016;70:104-7.

20. Herszényi L, Lakatos G, Hritz I, Varga MZ, Cierny G, Tulassay Z. The role of inflammation and proteinases in tumor progression. Dig Dis. 2012;30:249-54.

21. Şahin F, Aslan AF. Relationship between inflammatory and biological markers and lung Cancer. J Clin Med. 2018;7:pii: E160.

22. Hold GL, El-Omar EM. Genetic aspects of inflammation and cancer. Biochem J. 2008:410:225-35.

23. Maletzki $C$, Emmrich J. Inflammation and immunity in the tumor environment. Dig Dis. 2010;28:574-8.

24. Mantovani A, Allavena P, Sica A, Balkwill F. Cancer-related inflammation. Nature. 2008:454:436-44

25. Sun $\mathrm{SY}$, Zhao BQ, Wang J, Mo ZX, Zhao YN, Wang Y, et al. The clinical implications of mean platelet volume and mean platelet volume/platelet count ratio in locally advanced esophageal squamous cell carcinoma. Dis Esophagus. 2018;31

26. Yun $Z Y$, Li N, Zhang $X$, Zhang $H, B u$ Y, Sun $Y$, et al. Mean platelet volume, platelet distribution width and carcinoembryonic antigen to discriminate gastric cancer from gastric ulcer. Oncotarget. 2017;8: 62600-5.

27. Aksoy S, Kilickap S, Hayran M, Harputluoglu H, Koca E, Dede DS, et al. Platelet size has diagnostic predictive value for bone marrow metastasis in patients with solid tumors. Int I Lab Hematol. 2008;30:214-9.

28. Semple JW, Italiano JE Jr, Freedman J. Platelets and the immune continuum. Nat Rev Immunol. 2011;11:264-74. 
29. Refaai MA, Phipps RP, Spinelli SL, Blumberg N. Platelet transfusions: impact on hemostasis, thrombosis, inflammation and clinical outcomes. Thromb Res. 2011;127:287-91.

30. Sierko E, Wojtukiewicz MZ. Platelets and angiogenesis in malignancy. Semin Thromb Hemost. 2004;30:95-108.

31. Kapur R, Semple JW. Platelets as immune-sensing cells. Blood Adv. 2016;1: $10-4$.

32. Stokes KY, Granger DN. Platelets: a critical link between inflammation and microvascular dysfunction. J Physiol. 2012;590:1023-34.

33. Cengiz M, Şahin A, Özdil K, Sökmen HM. Role of RDW and MPV in diagnosis of colorectal polyps and carcinoma: a case-control study. Acta Oncol Tur. 2015:48:1-7.

34. Inagaki N, Kibata K, Tamaki T, Shimizu T, Nomura S. Prognostic impact of the mean platelet volume/platelet count ratio in terms of survival in advanced non-small cell lung cancer. Lung Cancer. 2014;83:97-101.

35. Peng $H X$, Yang L, He BS, Pan YQ, Ying HQ, Sun HL, et al. Combination of preoperative NLR, PLR and CEA could increase the diagnostic efficacy for IIII stage CRC. J Clin Lab Anal. 2017;31.

36. Hu H, Yao X, Xie X, Wu X, Zheng C, Xia W, et al. Prognostic value of preoperative NLR, dNLR, PLR and CRP in surgical renal cell carcinoma patients. World J Urol. 2017;35:261-70.

37. Gasparyan AY, Ayvazyan L, Mikhailidis DP, Kitas GD. Mean platelet volume: a link between thrombosis and inflammation? Curr Pharm Des. 2011;17:47-58.

Ready to submit your research? Choose BMC and benefit from:

- fast, convenient online submission

- thorough peer review by experienced researchers in your field

- rapid publication on acceptance

- support for research data, including large and complex data types

- gold Open Access which fosters wider collaboration and increased citations

- maximum visibility for your research: over $100 \mathrm{M}$ website views per year

At BMC, research is always in progress.

Learn more biomedcentral.com/submissions 